\title{
Performance Limiting Micropipe Defects in Silicon Carbide Wafers
}

\author{
Philip G. Neudeck, Member, IEEE and J. Anthony Powell, Member, IEEE
}

\begin{abstract}
We report on the characteristics of a major defect in mass-produced silicon carbide wafers which severely limits the performance of silicon carbide power devices. Micropipe defects originating in $4 \mathrm{H}$ - and $6 \mathrm{H}-\mathrm{SiC}$ substrates were found to cause preavalanche reverse-bias point failures in most epitaxially-grown pn junction devices of $1 \mathrm{~mm}^{2}$ or larger in area. Until such defects are significantly reduced from their present density (on the order of 100's of micropipes $/ \mathrm{cm}^{2}$ ), silicon carbide power device ratings will be restricted to around several amps or less.
\end{abstract}

\section{INTRODUCTION}

$\mathbf{S}$ LICON carbide enjoys some outstanding material property advantages over silicon for use in solid-state power semiconductor device applications. These include a higher breakdown field (five times that of $\mathrm{Si}$ ) that permits much smaller drift regions (i.e., much lower drift region resistances), a higher thermal conductivity (three times that of $\mathrm{Si}$ ) that permits better heat dissipation, and a wide bandgap energy $(2.9 \mathrm{eV}$ for $6 \mathrm{H}-\mathrm{SiC}, 3.2 \mathrm{eV}$ for $4 \mathrm{H}-\mathrm{SiC})$ that enables higher junction operating temperatures. A recent theoretical appraisal conducted by Bhatnagar and Baliga [1] indicates that $6 \mathrm{H}-\mathrm{SiC}$ power MOSFET's and diode rectifiers would operate over higher voltage and temperature ranges, have superior switching characteristics, and yet have die sizes nearly twenty times smaller than correspondingly rated silicon-based devices.

Since commercial one-inch diameter wafers of silicon carbide have become available only as recently as 1989 , SiC semiconductor technology is relatively young and unoptimized compared to silicon. Nevertheless, some extremely promising power device characteristics have been demonstrated in prototype $6 \mathrm{H}-\mathrm{SiC}$ diodes, MOSFET's, BJT's, and thyristors that were produced using nonoptimized fabrication processes [2]-[5]. However, these results were all obtained on smallarea devices, which are not reflective of the large areas and operating currents required for most power applications. To date, there have been no reports of larger-area (greater than several $\mathrm{mm}^{2}$ ) high-current (greater than several amps) $6 \mathrm{H}-\mathrm{SiC}$ power devices fabricated on mass-produced $\mathrm{SiC}$ wafers.

This paper reports on the identification and characteristics of a major defect in mass-produced $6 \mathrm{H}-$ and $4 \mathrm{H}-\mathrm{SiC}$ wafers which severely limits the areas and operating currents of silicon carbide power devices. This defect must be dealt with through improvements in bulk $\mathrm{SiC}$ crystal growth before truly advantageous silicon carbide power devices can be realized.

Manuscript received October 12, 1993; revised November 29, 1993. The authors are with NASA Lewis Research Center, Cleveland, OH 44135. IEEE Log Number 9215385.

\section{EXPERIMENT}

The bulk of the investigation was conducted using several lots of epitaxially-grown $6 \mathrm{H}-\mathrm{SiC}$ pn junction diodes and one lot of $4 \mathrm{H}-\mathrm{SiC}$ pn diodes. The devices were fabricated starting from commercially available 6H [6] and 4H [7] (0001) siliconface $\mathrm{SiC}$ substrates. Using atmospheric pressure chemical vapor deposition [8], [9], a variety of pn diode structures were homoepitaxially grown onto the $\mathrm{SiC}$ wafers. The lighterdoped sides of the $6 \mathrm{H}$ junction epilayers were all at least $4 \mu \mathrm{m}$ thick and doped less than $2 \times 10^{16} \mathrm{~cm}^{-3}$. Based on the high breakdown fields that have been experimentally observed on small-area $6 \mathrm{H}-\mathrm{SiC}$ pn diodes [5], [10], the blocking voltages of these devices should have been greater than $1000 \mathrm{~V}$ [11]. Each substrate was cut into individual $1 \mathrm{~mm} \times 1 \mathrm{~mm}$ square devices using a dicing saw. The resulting $1 \mathrm{~mm}^{2}$ devices were $I V$ tested on a probing station using computer controlled source/measure units with tungsten probe tips directly contacting the heavily doped cap layers and the substrate chuck contacting the backside of the wafer. The absence of contact metallizations facilitated unobscured viewing of the entire device area and did not hinder determination of the general rectification behavior of the diodes.

A small number of the $1 \mathrm{~mm}^{2}$ area $6 \mathrm{H}$ pn diodes exhibited rectification to reverse voltages beyond $1000 \mathrm{~V}$. However, greater than $80 \%$ of the $1 \mathrm{~mm}^{2}$ diodes failed at reverse voltages below $500 \mathrm{~V}$, well below predicted avalanche breakdown values. The typical reverse failure characteristics for a series of $1 \mathrm{~mm}^{2}$ devices cut from the same $n^{+} p 6 \mathrm{H}$ epilayered wafer are shown in Fig. 1. These failure characteristics were qualitatively analogous to those observed on all the epitaxial diode samples investigated in this work. At smaller reverse voltages, devices from the same wafer exhibited comparable leakages. When the reverse bias was further increased however, the devices each suffered a substantial sudden increase in current at largely differing voltages. The voltage at which the current suddenly increased is defined as $V_{\mathrm{JFai}}$, the junction failure voltage unique to each device. The failures did not appear to damage the devices, as the $I V$ characteristics were repeatable over many sweeps. When the reverse-biased diodes are microscopically observed in the dark on a probing station, clear evidence emerges that the junction failure takes place at specific points. The photograph of Fig. 2 shows the highly localized microplasmas that typically become visible when the $1 \mathrm{~mm}^{2} 6 \mathrm{H}-$ and $4 \mathrm{H}-\mathrm{SiC}$ pn diodes are reverse-biased beyond $V_{\mathrm{JFail}}$ on a probing station. Each point microplasma became visible at its own unique voltage, with no microplasmas being visible until the applied reverse bias exceeded $V_{\text {JFail }}$ for each 


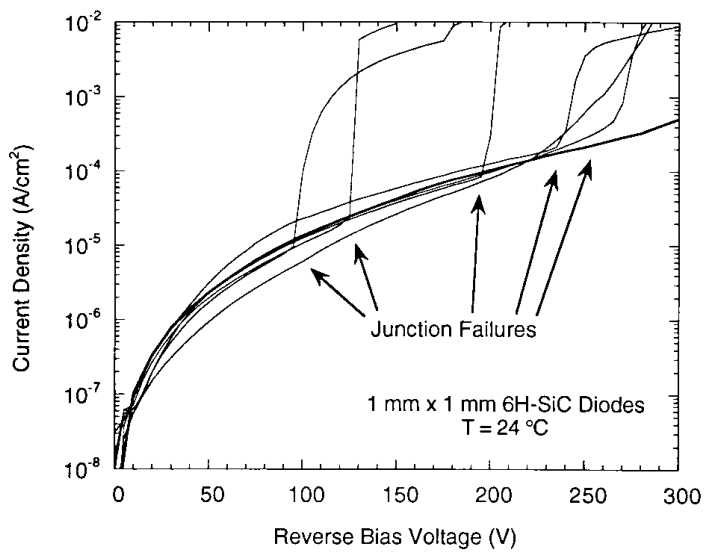

Fig. 1. Reverse current-voltage characteristics of a typical batch of $1 \mathrm{~mm} \times 1$ $\mathrm{mm} 6 \mathrm{H}-\mathrm{SiC}$ pn diodes produced on the same wafer. The diodes fail at differing voltages well below the $6 \mathrm{H}-\mathrm{SiC}$ avalanche breakdown field due to the presence of localized defects in the junctions.

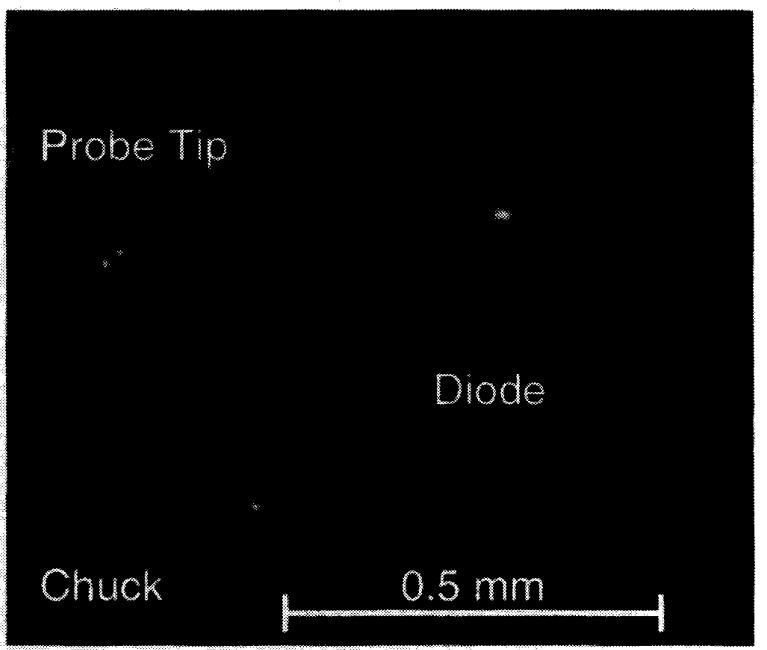

Fig. 2. Point-microplasmas observed in the dark on a probing station when a $1 \mathrm{~mm}^{2} 6 \mathrm{H}-\mathrm{SiC}$ pn diode is reverse-biased beyond its failure voltage $V_{\mathrm{JF} \text { ail }}$.

device. Though some diodes were observed to have failed along the saw-cut pn junction periphery, the vast majority of diode point failures occurred within the bulk junction area.

Since the high-voltage performance reported in small-area $6 \mathrm{H}-\mathrm{SiC}$ pn junctions does not apparently translate into largerarea devices, identification of the defect responsible is clearly of great importance. Reproducible SiC wafers like those employed in this work are presently grown using the boule sublimation growth technique [12]-[15]. These wafers are known to contain micropipe defects (also referred to as micropore, microtube, capillary, or pinhole defects) which run perpendicular to the polished wafer surface roughly parallel to the crystallographic c-axis [16]-[18]. The density of the micropipes observed in this work was on the order of 100's of micropipes $/ \mathrm{cm}^{2}$ in the boule-grown $6 \mathrm{H}-\mathrm{SiC}$ wafers, consistent with those densities reported by others [3], [16]. Previously, these defects have been shown to adversely affect $6 \mathrm{H}-\mathrm{SiC}$ LED's [16].

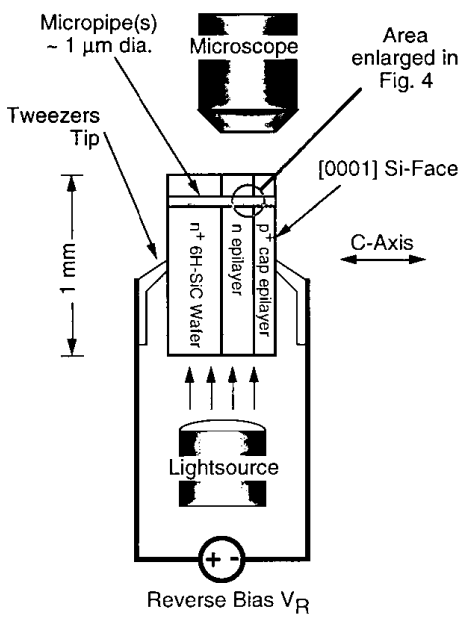

Fig. 3. Transmission optical microscopy setup ùsed to view $6 \mathrm{H}-\mathrm{SiC}$ micropipes. The positions of micropipes within the $1 \mathrm{~mm}^{2}$ diode areas were ascertained using the edge-on viewing technique, and were found to correlate with the positions of failure microplasmas (Fig. 2) in the majority of cases. The application of bias facilitated the direct observation of failure microplasmas in the micropipes (Fig. 4).

The tubal diameter of visible substrate micropipes varies roughly on the order of a micron, so the micropipes are observable when the $1 \mathrm{~mm}^{2}$ samples are viewed edge-on with optical transmission microscopy as illustrated in Fig. 3. Using this technique, the positions of the micropipes within the $1 \mathrm{~mm}^{2}$ diode sample areas were ascertained. These positions were then compared with the positions of localized microplasmas observed during reverse junction failures (Fig. 2 ). In the majority of diodes cataloged, the positions of failure microplasmas corresponded to micropipe locations.

Even greater evidence of the link between epitaxial pn junction failure and micropipe defects is shown in Fig. 4. The photograph in this figure is an extreme close-up of the micropipes running through the epitaxial metallurgical pn junction of a $6 \mathrm{H}$ device while biased at a reverse voltage in excess of $V_{\mathrm{JFai}}$. On all samples observed with this technique, the failure microplasmas were localized at the micropipes, and were only visible when the pn junction was biased beyond $V_{\text {JFail }}$. This and other extreme close-up edge-on views collected in our work verify that the $4 \mathrm{H}-$ and $6 \mathrm{H}-\mathrm{SiC}$ substrate micropipe defects cause harmful electrical consequences, even in epitaxially grown devices.

It is worth noting that we have not observed micropipes in SiC crystals grown by the Lely technique [19] (which are not generally considered suitable for mass production), nor has there been any reported in the literature.

\section{DISCUSSION AND SUMMARY}

The establishment of micropipes in mass-produced $4 \mathrm{H}$ - and $6 \mathrm{H}-\mathrm{SiC}$ wafers as a defect limiting the areas of high-voltage pn junctions has grave near-term implications concerning the realization of high-current silicon carbide power devices. As an example, the less than $20 \%$ present-day yield for device sizes of $1 \mathrm{~mm}^{2}$ would practically limit the operating current 


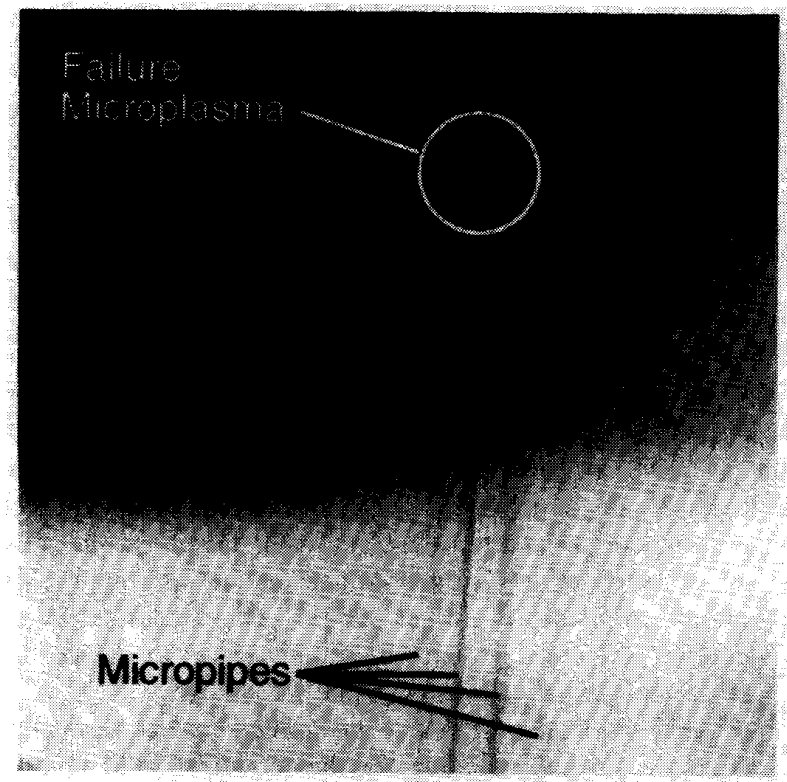

Fig. 4. Transmission optical micrograph $(\sim 400 \mathrm{X})$ of point microplasma viewed edge-on during failure. The microplasma is only visible when the diode is reverse-biased beyond its failure voltage $\left(V_{\mathrm{JFail}}\right)$, and its location roughly corresponds to the position of the metallurgical pn junction (Fig. 3).

of a $3000 \mathrm{~V}$ unipolar $6 \mathrm{H}-\mathrm{SiC}$ power device to approximately $1 \mathrm{~A}$, assuming the device was operating near its theoretical maximum current density of around $100 \mathrm{~A} / \mathrm{cm}^{2}[1]$. Though a family of small-area $\mathrm{SiC}$ power devices could offer advantages in high-temperature operation, switching speed, and radiation hardness [1], [20], [21], the voltage and current ratings of silicon carbide power devices will not out-perform existing silicon power devices until improvements in $\mathrm{SiC}$ crystal growth enable larger defect-free areas.

Two possible mechanisms for micropipe formation have been put forth to date. The first suggests that micropipes are open core super screw dislocations that propagate along the $\mathrm{C}$-axis from the seed crystal during growth [22]. The second is based upon contaminant particles introduced during the growth process [18]. Therefore, we speculate that minimization of both contaminants and seed crystal dislocations should reduce micropipe densities. Palmour, et al. recently reported a $50 \%$ reduction in micropipe density to approximately 150 micropipes $/ \mathrm{cm}^{2}$ in $6 \mathrm{H}$ wafers [3], but the methods used to attain the improvement were not revealed. Nevertheless, it is the authors' opinion that the eradication of defects from $4 \mathrm{H}-$ and $6 \mathrm{H}-\mathrm{SiC}$ wafers and epilayers remains paramount and should be pursued vigorously so that the considerable theoretical promise of silicon carbide power devices can be fulfilled.

\section{REFERENCES}

[1] M. Bhatnagar and B. J. Baliga, "Comparison of $6 \mathrm{H}-\mathrm{SiC}, 3 \mathrm{C}-\mathrm{SiC}$, and Si for power devices," IEEE Trans. Electron Devices, vol. 40, no, 3, pp. 645-655, March 1993.
[2] M. Bhatnagar, P. K. McLarty, and B. J. Baliga, "Silicon-carbide highvoltage $(400 \mathrm{~V})$ Schottky barrier diodes," IEEE Electron Device Lett., vol. 13 , no. 10 , pp. 501-503, October 1992

[3] J. W. Palmour, J. A. Edmond, and C. H. Carter Jr., "Demonstrating the potential of $6 \mathrm{H}$-silicon carbide for power devices," presented at $51 \mathrm{st}$ Annual Device Res. Conf., Santa Barbara, CA, June 1993.

[4] J. W. Palmour, J. A. Edmond, and C. H. Carter Jr., "High temperature rectifiers and MOS devices in $6 \mathrm{H}$-silicon carbide," U.S. Army Research Office, Research Triangle Park, NC, Tech. Rep. ARO 29096.1-EL-S, August 1992.

[5] J. A. Edmond, D. G. Waltz, S. Brueckner, H.-S. Kong, J. W. Palmour, and C. H. Carter Jr., "High temperature rectifiers in 6H-silicon carbide," in Trans. Ist Int. High Temperature Electron. Conf., Albuquerque, NM, June 1991, pp. 207-212.

[6] Cree Research, Inc., 2810 Meridian Parkway, Suite 176, Durham, NC 27713

[7] Moltech Corporation, Engineering Building, SUNY, Stony Brook, NY 11794-2280.

[8] J. A. Powell, D. J. Larkin, L. G. Matus, W. J. Choyke, J. L. Bradshaw, L. Henderson, M. Yoganathan, J. Yang, and P. Pirouz, "Growth of high quality $6 \mathrm{H}-\mathrm{SiC}$ epitaxial films on vicinal (0001) 6H-SiC wafers," Appl. Phys. Lett., vol. 56, no. 15, pp. 1442-1444, April 1990.

[9] J. A. Powell, J. B. Petit, and L. G. Matus, "Advances in silicon carbide chemical vapor deposition (CVD) for semiconductor device fabrication," Trans. 1st Int. High Temperature Electron. Conf., Albuquerque, NM, June 1991, pp. 192-197.

[10] L. G. Matus, J. A. Powell, and C. S. Salupo, "High-voltage 6H-SiC p-n junction diodes," Appl. Phys. Lett., vol. 59, no. 14, pp. 1770-1772, September 1991.

[11] B. J. Baliga, Modern Power Devices, 1st ed. New York: Wiley, 1987.

[12] Y. M. Tairov and V. F. Tsvetkov, "Investigation of growth processes of ingots of silicon carbide single crystals," J. Cryst. Growth, vol. 43, pp. 209-212, February 1978.

[13] G. Ziegler, P. Lanig, D. Theis, and C. Weyrich, "Single crystal growth of $\mathrm{SiC}$ substrate material for blue light emitting diodes," IEEE Trans. Electron Devices, vol. 30, no. 4, pp. 277-281, April 1983.

[14] C. H. Carter Jr., L. Tang, and R. F. Davis, "Growth of single crystal boules of $\alpha(6 \mathrm{H})-\mathrm{SiC}$," presented at the Fourth Nat. Rev. Meeting on the Growth and Characterization of SiC, Raleigh, NC, June 1987.

[15] D. L. Barrett, R. G. Seidensticker, W. Gaida, R. H. Hopkins, and W. J. Choyke, "SiC boule growth by sublimation vapor transport," J. Cryst. Growth, vol. 109, pp. 17-23, 1991.

[16] K. Koga, Y. Fujikawa, Y. Ueda, and T. Yamaguchi, "Growth and characterization of $6 \mathrm{H}-\mathrm{SiC}$ bulk crystals by the sublimation method," in Springer Proc. in Physics, vol. 71, Amorphous and Crystalline Silicon Carbide IV, C. Y. Yang, M. M. Rahman, and G. L. Harris, Eds. Berlin: Springer-Verlag, 1992, pp. 96-100.

[17] P. A. Glasow, "6H-SiC studies and developments at the corporate research laboratory of Siemens AG and the Institute for Applied Physics of the University in Erlangen (FRG)," in Springer Proc. in Physics, vol. 34, Amorphous and Crystalline Silicon Carbide, G. L. Harris and C. Y.-W. Yang, Eds. Berlin: Springer-Verlag, 1989, pp. 13-33.

[18] J.-W. Yang, "SiC: problems in crystal growth and polytypic transformation," Ph.D. dissertation, Case Western Reserve Univ., Cleveland, $\mathrm{OH}$ May 1993.

[19] J. A. Lely, "Darstellung von einkristallen von silicium carbid und Beherrschung von art und menge der eingebautem verunreingungen," Ber. Deut. Keram. Ges., vol. 32, pp. 229-236, August 1955.

20] R. F. Davis, G. Kelner, M. Shur, J. W. Palmour, and J. A. Edmond, "Thin film deposition and microelectronic and optoelectronic device fabrication and characterization in monocrystalline alpha and beta silicon carbide," Proc. IEEE, vol. 79, no. 5, pp. 677-701, May 1991

21] J. M. McGarrity, F. B. McLean, W. M. DeLancey, J. Palmour, C. Carter, J. Edmond, and R. E. Oakley, "Silicon carbide JFET radiation response," IEEE Trans. Nucl. Sci., vol. 39, no. 6, pp. 1974-1981, December 1992.

[22] S. Wang, M. Dudley, C. Carter Jr., D. Asbury, and C. Fazi, "Characterization of defect structures in $\mathrm{SiC}$ single crystals using synchrotron X-ray topography," Materials Res. Soc. Symposia Proc, vol. 307, Applicat. of Synchrotron Radiation Techniques to Materials Sci., D. L. Perry, N. D. Shinn, R. L. Stockbauer, K. L. D'Amico, and L. J. Terminello, Eds. Pittsburgh: Materials Research Society, 1993, pp. 249-254. 